Andrzej Kraslawski and Ilkka Turunen (Editors) Proceedings of the $23^{\text {rd }}$ European Symposium on Computer Aided Process Engineering - ESCAPE 23 June 9-12, 2013, Lappeenranta, Finland,

(C) 2013 Elsevier B.V. All rights reserved.

\title{
Energy Integration in the cement industry
}

\author{
Alberto Mian, ${ }^{\mathrm{a}}$ Matthias Bendig,, Gaia Piazzesi, ${ }^{\mathrm{a}}$ Giovanni Manente, ${ }^{\mathrm{b}}$ Andrea \\ Lazzaretto, ${ }^{\mathrm{b}}$ François Maréchal ${ }^{\mathrm{a}}$ \\ ${ }^{a}$ École Polytechnique Fédérale de Lausanne, Lausanne 1015, Switzerland \\ ${ }^{b}$ Università degli Studi di Padova, Padova, Italy \\ alberto.mian@epfl.ch
}

\begin{abstract}
Cement production is an energy intensive industrial process that requires heat to be supplied at high temperature levels under the constraints of gas-solid heat exchange phenomena and the kinetics of chemical reactions. In this paper, the use of Pinch Analysis and Process Integration techniques to optimize the energy efficiency of the cement production will be explored. The aim is to use process modeling to characterize cooling and heating requirements of the process, focusing on the gas-solid heat exchanges while including waste fuel utilization. The heat cascade model is adapted to account for gas-solid and gas-gas heat recovery used to calculate the heat recovery in the process.

A mixed integer linear programming problem is solved to calculate the integration of the available heat; this model optimizes the heat recovery and the energy conversion efficiency considering different fuels, heat recovery options and process operating conditions.
\end{abstract}

Keywords: Energy Integration, Pinch Analysis, Cement. Introduction

\section{Introduction}

Cement production is a thermal energy intensive process, which requires heating solid particles up to $1450^{\circ} \mathrm{C}$ and cooling it down. The process generates hot and $\mathrm{CO}_{2}$ rich exhaust streams. Fin order to study energy efficiency of the process, authors like Mujumdar et al. $(2006,2007)$ developed detail models of process units, while others highlighted energy and exergy performances of plants (Kolip et al 2010). Some authors have studied the integration of cogeneration units in cement industry as an option of waste heat recovery (Wang et al 2008). The previously mentioned studies are considering, in detail, thermodynamic performances, but they are not investigating the heat integration inside the process. Some other authors, such as Murray et al (2008), Kantee (2004), Mokrzycki (2003) have focused their analysis in the use of alternative/waste fuels, but they did not show the impact and the potential of these fuels on the heat integration between streams.

This paper explores the use of process integration techniques to improve the energy efficiency of cement plants, focusing on the dry route cement production and the integration of alternative fuels. Flow sheeting modeling, Pinch Analysis and mixed integer linear optimization techniques are applied to study an existing cement production facility.

\section{Process description and modeling methodology}

Following a systematic synthesis approach, the model of the cement plant (Figure 1) is built using a flow sheeting software (Belsim Vali, 2010). The design specification is the 
size of the plant, set considering a daily clinker production of 2400 tons. The model defines the primary energy requirements (expressed in $\mathrm{MJ} /$ ton $_{\text {clinker }} /$ day) and characterizes the temperature-enthalpy profiles of the heat transfer requirements in each process unit.

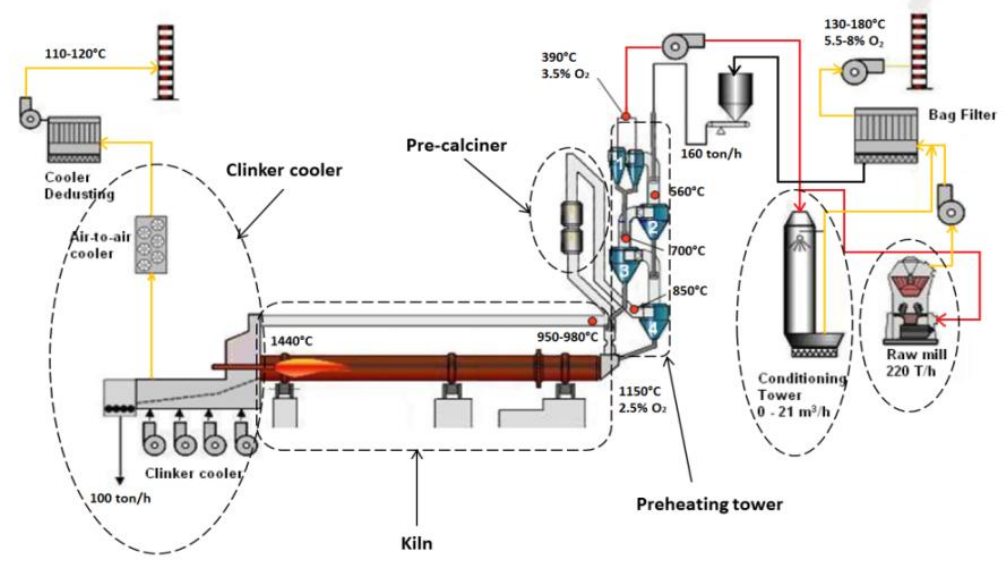

Figure 1: Investigated plant configuration

The identification of heat requirements related to chemical reactions and heat transfer phenomena occurring between mixed solid and gaseous streams is one of the major keypoint of this study since the majority of process units (preheating tower, calciner, rotary kiln and clinker cooler) are characterized by direct heat exchange. A specific approach is used to correctly consider direct heat exchange between solids and gases. To precisely capture the temperature-enthalpy profiles, process units are modeled as a set of discretized cells (Fig.2), in which solid and gas streams are kept separated in sub-cell structures. Between the gas and the solid sub-cell $i$ the exchange of heat and gaseous reaction products, if any, is considered.

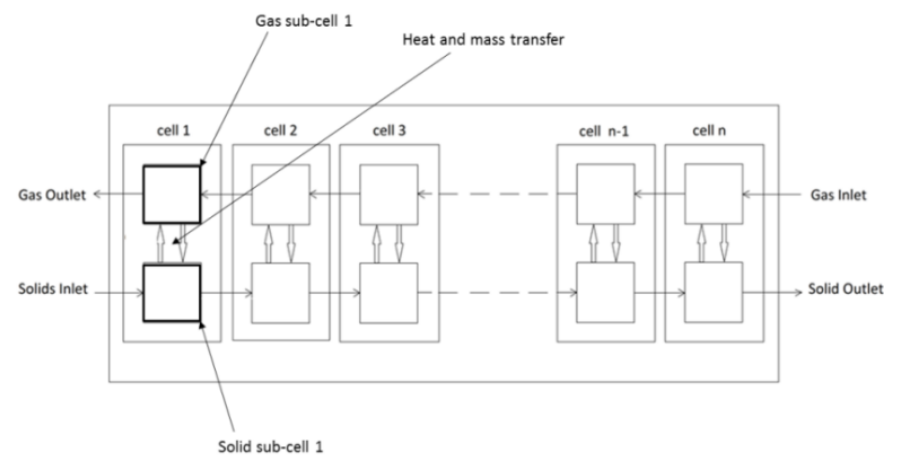

Figure 2: Discretization in cells and sub-cells to account interactions between solids and gases

The non-linearity of temperature-enthalpy profile is modeled considering piecewise linear parameterization with zero order continuity. Depending on the availability of measurements and data, the inlet and outlet temperature levels of the gas stream or solid stream, together with the involved heat loads, are calculated. Thermal heat losses are modeled for each unit as a function of the mean temperature. In preheating section, the 
thermal losses of the cyclones vary from $15 \%$ to $20 \%$ of the heat delivered by the hot gases. A thermal efficiency of $85 \%$ is obtained for the calciner unit.

A particular case is the model of the kiln, in which the discretization in cells is done with respect to the profile of chemical species concentration inside the unit, which is related with temperature levels. The reaction kinetics concerning the clinker process (Mujumdar, 2007) are accounted in the piecewise linearization. At the same time the separation of carbon dioxide generated by calcination reaction is modeled assuming that the calcination reaction takes place for $65 \%$ in the in-line calciner and that it is completed in the rotary kiln.

Finally, in order to estimate the heat availability from alternative fuels burning and the corresponding temperature profile, a set of independent burner models have been developed. Alternative fuels compositions and the corresponding excess air are set according to (Kääntee 2003), ( Mokrzycki 2003) and (Murray 2008). Both fuel and air streams are considered entering the system at ambient conditions.

\section{Heat transfer model}

Concerning the model of the heat transfer, the heat cascade is modeled using stream dependent minimum approach temperature contribution $\left(\Delta \mathrm{T}_{\min } / 2\right)$, which accounts for the heat transfer coefficient and heat transfer phenomena. Although the concept of minimum approach temperature was developed for indirect heat exchange, it adapted here for the direct solid-gas exchange. The minimum approach temperature contributions are calibrated using heat transfer correlations, which are available in literature, and existing plant measurements. For cyclones and fluidized beds data of Rajan (2008) and Shimizu (2004) have been used. In cyclones and calciner units, the heat transfer coefficient is estimated as a function of the specific heat exchange area, the mean logarithmic temperature difference between hot and cold streams and the specific heat exchanged.

$$
k=\frac{q}{A \cdot \Delta T_{m l}}
$$

As reported by Rajan (Rajan 2008), by measuring the total weight of the particles in the cyclone $M_{h}$, at each interval of time, the density of solid particles $\rho_{s}$, and the particles diameter $d_{p}$, the heat transfer area in cyclones and calciner can be expressed as:

$$
A=\frac{6 \cdot M_{h}}{\rho_{s} \cdot d_{p}}
$$

It has to be noted that the residence time of the particle acts as a constraints for the minimum temperature difference. Values between 50 and $100 \mathrm{~K}$ are finally obtained.

Concerning heat exchange phenomena occurring in rotary kilns, the heat is transferred by direct contact between gases and solids particles but also through the rotating kiln walls. In kiln unit, the heating and cooling requirements are separated as well as the contributions coming from the reacting solids, the combustion gases and the carbon dioxide gas, which is generated from calcination reaction. This analysis results into a list of heating and cooling requirements defined as separated temperature-enthalpy profiles. Assuming the $\Delta \mathrm{T}_{\min }$ values, the heat cascade model defines the possible heat recovery in the whole process.

\section{Energy integration model}

The overall heat requirement of the process is satisfied by fuels combustion. The Mixed Integer Linear Programming formulation of the heat cascade (Maréchal et al. 1998) is 
used to calculate the fuel flows (utility streams) that close the energy balance of the system at a minimum cost. The flow-related contribution of the different fuels is defined using the temperature-enthalpy profiles calculated by the individual fuel combustion models. The heating requirements for air and fuel preheating (cold streams) and the heat available from combustion gases (hot stream) are taken into account at this level.

Stating $y_{w}$ the integer variable associated with the use of the utility stream $w, c_{w}$ the cost related to the fuel utility $\mathrm{w}$, and $f_{w}$ the multiplication factor of the reference flow rate (associated to the w-th utility) and being $n_{w}$ the number of utility fuels streams and the number of process streams, the optimization problem is then:

$$
\min \sum_{w=1}^{n_{w}} y_{w} \cdot c_{w} \cdot f_{w}
$$

Subject to the heat cascade constraints:

$$
\begin{array}{ll}
\sum_{w=1}^{n_{w}} f_{w} \cdot \dot{q}_{w k}+\sum_{i=1}^{n} \dot{Q}_{i k}+\dot{R}_{k+1}-\dot{R}_{k}=0 & \forall k=1, \ldots, n_{k} \\
f_{\text {min }} \cdot y_{w} \leq f_{w} \leq f_{\text {max }} \cdot y_{w} \quad & \forall w=1, \ldots, n_{w} \\
y_{w} \in\{0,1\} & \\
\dot{R}_{k}=0 ; \quad \dot{R}_{1}=0 ; \dot{R}_{n_{k+1}}=0 & \forall k=1, \ldots, n_{k+1}
\end{array}
$$

In particular, $\dot{R}_{k}$ represents the energy cascaded from the corrected temperature interval $k$ to the lower one in the heat cascade, $\dot{Q}_{i k}$ is the heat load of the process stream $i$ in the interval $k$. Concerning the utility streams, $\dot{q}_{w k}$ represents the heat load of the utility $w$ in the interval $k$ for a given reference flow-rate, $f_{\min }$ and $f_{\max }$ refer to the minimum and maximum values accepted for $f_{w}$. Eq. 7 guaranties that the overall energy balance is satisfied using the proposed utility streams. In order to differentiate the different fuels quality, we defined the fuel $\cos t c_{w}$ as being the exergetic value of the heat delivered the combustion calculated by Eq. 8 .

$$
c_{w}=L H V_{w} \cdot\left(1-\frac{T_{a}\left(\ln \left(T_{a d_{w}}\right)-\ln \left(T_{0}\right)\right)}{\left(T_{a d_{w}}-T_{0}\right)}\right)
$$

Where $T_{a}[\mathrm{~K}]$ is the ambient temperature, $T_{a d_{w}}[\mathrm{~K}]$ is the adiabatic temperature of stoichiometric combustion, $T_{0}[\mathrm{~K}]$ is the reference state temperature $(298 \mathrm{~K})$ and $L H V_{w}$ $[\mathrm{kJ} / \mathrm{kg}]$ is the lower heating value of fuel $\mathrm{w}$.

\section{Results and conclusion}

Using the flow sheet model of the studied plant, a primary energy consumption of 3600 $\mathrm{MJ} / \mathrm{ton}_{\text {clinker }}$ is calculated. This is consistent with the mean thermal energy consumption reported for typical European plants (EU 2010). Fig. 3 presents the composite curves of the present situation. By applying the process integration model, the thermal energy demand target is calculated to be $2515 \mathrm{MJ} /$ ton $_{\text {clinker, }}$, corresponding to a reduction of almost $30 \%$. The integration of alternative/waste fuels burning with excess air and fuel preheating, leads to the activation of Pinch Point at high temperature (Fig 4.a). The Composite Curves reflect a higher level of heat recovery and a better integration of the combustion gases. By analyzing the Carnot Grand Composite Curve (Fig. 4b) it is possible to visualize the heat rejected, the shaded area represents the potential of waste heat valorization by integrating Rankine cycles. This shaded area shows a waste heat

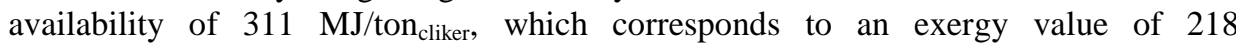




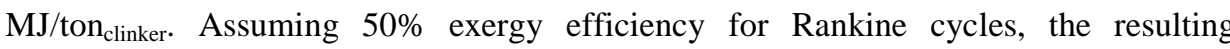
electricity production potential is $109 \mathrm{MJ}_{\text {ton }}$ clinker. The reduction of carbon dioxide emissions is then calculated, taking into account the negative impact which derives from electricity production potential. Considering an emission of $0,45 \operatorname{ton}_{\mathrm{CO} 2} / \mathrm{MWh}_{\mathrm{el}}$ for the EU electricity mix production, the carbon dioxide emissions can be reduced from the actual 0,9 ton $_{\mathrm{CO} 2} /$ ton $_{\text {clinker }}$ to 0,684 ton $_{\mathrm{CO} 2} /$ ton $_{\text {clinker }}$, which correspond to an emission reduction of $24 \%$.

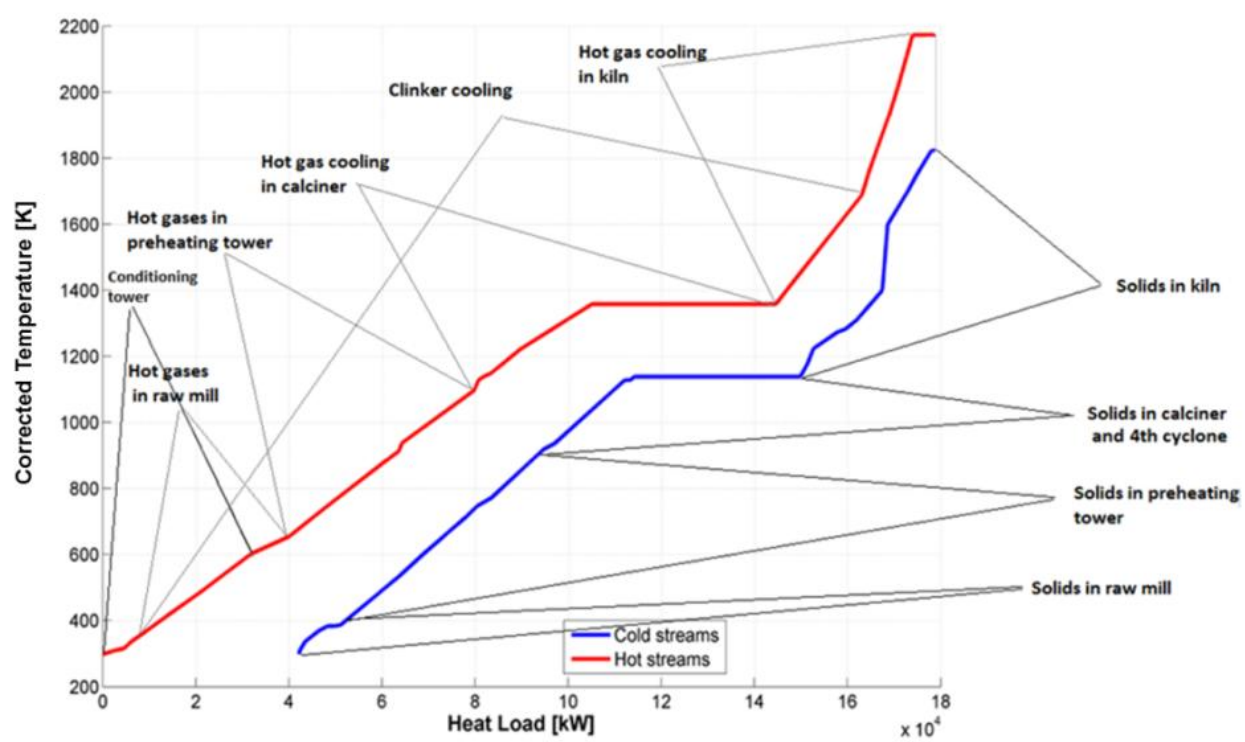

Figure 3: Composite Curves for the studied cement production plant

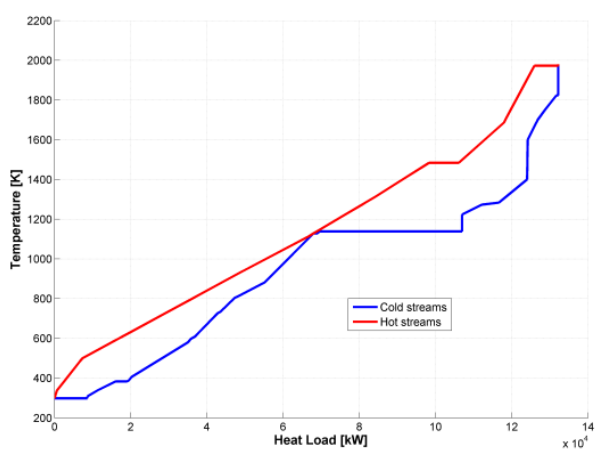

(a)

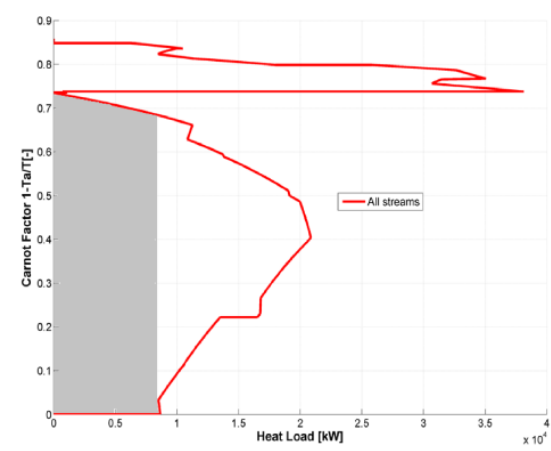

(b)

Figure 4: Composite Curve of the optimized case study (a) and corresponding Exergy Grand Composite Curve (b)

As a conclusion, the adaptation of the process integration techniques to the cement production process, allows targeting innovative cement production, calculating the optimal configuration of fuel feed, and finally reducing thermal energy needs and 
carbon dioxide emissions. The constraints related to use/management of waste fuels are of primary importance, and need to be better evaluated in future work.

\section{References}

European Commission, Reference Document on Best Available Techniques in the Cement, Lime, and Maghesium Oxide Manufacturing Industries, May 2010

F. Maréchal, B. Kalitventzeff, 15 March 1998, Process integration: Selection of the optimal utility system, Computers \&amp; Chemical Engineering, Volume 22, Supplement 1, Pages S149S156.

U. Kääntee, R. Zevenhoven, R. Backman, M. Hupa,2004, Cement manufacturing using alternative fuels and the advantages of process modelling, Fuel Processing Technology, Volume 85, Issue 4

A.Kolip and A.F.Savas, 2001, Energy and exergy analyses of a parallel flow, four stage cyclone precalciner type cement plant, International Journal on the Physical Sciences, Turkey 2010

B.Linnhoff, 1982, A user guide on process integration for the efficient use of energy, Institution of Chemical Engineers

K.S. Mujumdar, V.V. Ranade,2006, Simulation of Rotary Cement Kilns Using a OneDimensional Model, Chemical Engineering Research and Design, Volume 84, Issue 3, Pages 165-177.

E Mokrzycki, Alicja Uliasz-Bocheńczyk, Mieczysław Sarna, January-February 2003, Use of alternative fuels in the Polish cement industry, Applied Energy, Volume 74, Issues 1-2, Pages $101-111$

K. S. Mujumdar, K.V. Ganesh, Sarita B. Kulkarni, Vivek V. Ranade,2007, Rotary Cement Kiln Simulator (RoCKS): Integrated modeling of pre-heater, calciner, kiln and clinker cooler, Chemical Engineering Science, Volume 62, Issue 9, Pages 2590-2607.

A.Murray and L.Prince, Use of Alternative Fuels in Cement Manufacture> Analysis of Fuel Characteristics and Feasibility for Use in the Chinese Cement Sector, Energy and Resources Group, UC Berkeley, USA 2008

K.S. Rajan, K. Dhasandhan, S.N. Srivastava, B. Pitchumani, June 2008, Studies on gas-solid heat transfer during pneumatic conveying, International Journal of Heat and Mass Transfer, Volume 51, Issues 11-12, Pages 2801-2813.

E.Worrel, C.Galitsky \& Lynn Price, Energy efficiency Opportunities for the Cement Industries, LBNL, January 2008.

Utlu et al., Energy and exergy analyses of a raw mill in a cement production, Elsevier, Turkey 2005.

Z.Hu et al., Numerical simulation study on gas-solid two-phase flow in pre-calciner, Communications in Nonlinear Science and Numerical Simulation, Elsevier, China 2004.

A.Jain et al., Studies on Gas-Solid Heat Transfer in Cyclone Heat Exchanger, Journal of Heat Transfer, ASME, India 2006 